Balancing the needs and preferences of humans against concerns for fishes how to handle the emerging ethical discussions regarding capture fisheries?

Sandøe, Peter; Gamborg, Christian; Kadri, S.; Millar, K.

Published in:

Journal of Fish Biology

DOI:

10.1111/j.1095-8649.2009.02461.x

Publication date:

2009

Document version

Peer reviewed version

Citation for published version (APA):

Sandøe, P., Gamborg, C., Kadri, S., \& Millar, K. (2009). Balancing the needs and preferences of humans against concerns for fishes: how to handle the emerging ethical discussions regarding capture fisheries? Journal of Fish Biology, 75(10), 2868-2871. https://doi.org/10.1111/j.1095-8649.2009.02461.x 


\title{
Balancing the needs and preferences of humans against concerns for fish: How to handle the emerging ethical discussions regarding capture fisheries? ${ }^{1}$
}

\author{
Peter Sand $e^{12}$, Christian Gamborg ${ }^{1}$, Sunil Kadri ${ }^{23}$, Kate Millar $^{4}$ \\ ${ }^{1}$ Danish Centre for Bioethics and Risk Assessment, University of Copenhagen, Faculty of Life Sciences, \\ Rolighedsvej 25, 1958 Frederiksberg C, Denmark \\ ${ }^{2}$ Fish Biology Group, Institute of Biomedical \& Life Sciences, University of Glasgow, United Kingdom \\ ${ }^{3}$ Aquaculture Innovation, Glasgow, United Kingdom \\ ${ }^{4}$ Centre for Applied Bioethics, University of Nottingham, United Kingdom
}

\begin{abstract}
How can stakeholders within the fisheries community, engage in constructive ethical discussions? Drawing on experiences from previous debates surrounding the human use of animals, this paper presents a proactive approach whereby stakeholders can create a framework for ethical discussion of capture fisheries.
\end{abstract}

Key words: ethics; fish welfare; stakeholders; ethical debate

Until recently, the 'harvesting' of fish for human consumption was rarely raised as an issue for inclusion in society's ongoing discussions and ethical reflections about the use of animals. However, this is now changing and a range of ethical concerns has been raised by stakeholders from fish scientists and industry representatives through to environmental groups (Huntingford, 2006; Turnbull \& Kadri 2007). For some time, the hunting of various marine mammals has been subject to extensive ethical discussion concerning both animal welfare and conservation issues. Now, the welfare of farmed fish has been raised, as have ethical issues regarding the use of wild fish. Hence there is every reason to expect that the issue of fish welfare will

\footnotetext{
${ }^{1}$ The reference of the printed version is:

P. Sandøe, C. Gamborg, S. Kadri \& K. Millar (2009): Balancing the needs and preferences of humans against concerns for fish: How to handle the emerging ethical discussions regarding capture fisheries? Journal of Fish Biology 75(10): 2868-2871.

The definitive version is available at http://onlinelibrary.wiley.com/doi/10.1111/j.1095-8649.2009.02461.x/abstract

${ }^{2}$ Author to whom correspondence should be addressed. Tel.: +45 35333059; fax: +45 35336801; email: pes@life.ku.dk
} 
enter the broader capture fisheries discussion alongside the current discussion of conservation. However the discussion will probably be less heated and possibly more 'academic' because fish rank low on the sociozoological scale (cf. Arluke and Sanders 1996). Moreover, fisheries are often ingrained within the culture and traditions of countries with a coastline. However, the manner by which these ethical discussions have emerged is not unusual when seen in the context of previous debates on animal use.

Since the 1970's, other forms of animal use - for example farm animal production, commercial hunt of sea mammals and recreational hunting - have been the subject of extensive ethical discussion. When reviewing the development of these public discussions, several common elements emerge. Initially groups with a vested interest - such as farmers or hunters - argued that: a) this form of ethical discussion is not relevant or not a significant issue of concern in their particular context; and that b) those who raise these ethical questions represent extreme views and should therefore not be taken seriously in debates about good practice. However, on many occasions it emerged that this was not the case.

Therefore it may be claimed that the reluctance of those involved in a given form of animal use to engage in a genuine ethical debate resulted in a much more heated and unproductive process of discussion and change than would have been the case if interest groups had engaged in a productive manner from the outset. The ongoing Canadian seal hunting debate is possibly a good case to illustrate this point. Recently, the Canadian authorities have gone to great lengths to regulate the hunt in order that it be carried out in a humane manner. However, the early polarized debate about the killing of seal pups still looms large and influences public perceptions of all seal hunting and as a result impacts on international trade and consumer perception.

With the benefit of retrospective assessment, the lesson learnt in most of these cases is that it is better to engage in the debate as issues emerge internally or are raised externally. Rather than being a negative process, there are several benefits; firstly, proactive individuals or organizations can influence the way in which the debate develops and secondly one can use the engagement as a positive marketing asset.

In light of the discussions concerning different forms of animal use, it is argued that there is a need for substantial ethical debate on the human use of fish, regarding at least three matters: 1) needs and preferences of humans 2) concerns about the effects on fish; and 3) the overall ethical framework within which "ethical balancing" takes place. 
1) Needs and preferences. There are a number of issues raised by commercial fisheries that need to be discussed in depth. Some of the key issues include diminishing fish stocks with ensuing decreased sustainability of marine fishing areas. In addition, some of the fishing that takes place is done for purposes other than direct human consumption, and this raises the question of whether it is acceptable to use stocks of wild fish to produce feed for farm animals, including pigs, chickens and fish.

In terms of the impacts on specific communities, it is also important to consider that some regional fish stocks are being significantly depleted in order to serve global markets. Aside from the issues of transport costs and the so called environmental cost of 'food miles', local communities may not benefit from commercial fishing activities along their coastline, while bearing the direct costs of the depleted fish stocks and the subsequent knock-on effects that this can have on poor communities and local economies.

Moreover, it is important to clarify what count as 'needs' in relation to commercial fisheries. In relation to the needs of fishing communities (or nations), economic and rural development and the creation of jobs in marginalized areas may constitute important needs, but cultural traditions can also be significant. At the other end of the supply chain, consumers have needs in terms of diet, product price and quality. However the question of needs can be re-framed; the need for fish products may be met in other ways, for example through increased aquaculture production particularly focused on certain commercial species and / or geographical regions which could notably relieve pressure on wild fish stocks (see for example FAO 2007).

2) Effects on fish. Although this is a controversial area there appears to be growing evidence that at least teleost fish are able to experience pain and suffering that go beyond nociception processes. This debate is not dissimilar to past discussions of farmed animal welfare. For much of the $20^{\text {th }}$ century the nature and significance of farm animals' suffering were debated and contested. It is only in the last two decades with changing ethical sentiments towards animals, the advent of new welfare science research findings and the development of valuable welfare concepts (such as the Five Freedoms, originating with Brambell (1965) and the 12 criteria of animal welfare recently defined by the EU project Welfare Quality (Botreau et al. 2007)), that many practitioners acknowledge and prioritise approaches to significantly reduce farm animal suffering. Furthermore when reviewing the fish welfare debate, if the arguments against fish sentience are valid, these arguments could be extended to cover most farmed animal species (see for example Braithwaite and Huntingford 2004), which to most people will serve as a proof that these arguments must be flawed. If it were thus to be assumed that fish do indeed feel pain and are able to suffer in other ways, it then becomes important to discuss capture, handling and killing practices in commercial fisheries from the point of view of animal welfare. 
Another key area of debate, going beyond traditional welfare-oriented issues, concerns the protection of fish populations in their own right as well as the ecosystems of which they are part. Here commercial fishing may have profound effects. In this context the focus is on the welfare and survival of regional populations and species of fishes. Although discussion of respect for (aquatic) nature, which is often characterised as part of a more overarching environmental debate, is complex, it must remain part of the debate about fish welfare when discussing commercial fisheries. Concerns about protection of nature have influenced farm animal welfare policies, particularly in continental Europe and they are bound to play a part in shaping future policies concerning sustainable commercial fisheries.

3) Balancing. The ethical discussion of commercial fisheries inevitably involves a balancing of different concerns, perhaps most notably balancing the needs and preferences of humans against concerns for fish. However, it is important that the type of framework applied to facilitate the balancing process allows the inclusion of all relevant issues. Different ethical theories concerning what is considered an ethically acceptable use of animals can be applied here. There are ethical positions such as utilitarianism which allow for a genuine weighing of concerns, as well as other hybrid views that allow one to combine different ethical positions (Sandøe and Christiansen, 2008).

In addition, the ethical discussion must extend further than a comparison of the interests of fish versus the interests of man. Comprehensive discussions of the consequences for wild fish populations and the ecosystems in which they live are indeed relevant, as are discussions about consequences for vulnerable low income groups in developing countries who might otherwise have consumed the fish used by animal farming industries as fishmeal. This much broader discussion will be analogous to the increasing debate about the sustainability of farmed animal production systems.

A number of ethical frameworks, such as the Ethical Matrix method, have been developed to aid the mapping and weighing of issues (Millar et al., 2007). Tools of this nature can help fishery groups explore their perspectives, clarify areas of convergence and divergence within their positions, and therefore identify common ground through a process of facilitated, participatory discussion (for an example of operationalisation within fisheries, see Kaiser and Forsberg, 2001).

In light of the need for a wider ethical debate, those involved in commercial fisheries should aim to formulate coherent ethical positions and at the same time be willing to take a critical look at traditional practices. They should aspire to initiate a proactive approach whereby stakeholders can create a framework for ethical discussion of capture fisheries. As shown with other forms of animal use, such a debate is 
inevitable, if not seen by some as worthwhile in its own right. In addition, from a purely instrumental perspective the debate is crucial, as those who are mainly concerned about human interests (with regards to various forms of fish use) run a greater risk by avoiding the debate than they do by engaging in a constructive way.

\section{References}

Arluke, A. and Sanders, C.R. (1996) Regarding Animals. Philadelphia, PA: Temple University Press

Botreau R., Veissier I., Butterworth A., Bracke M.B.M. and Keeling L.J. 2007 Definition of criteria for overall assessment of animal welfare Animal Welfare 16: 225-228.

Braithwaite,V.A. and Huntingford, F.A.(2004) Fish and welfare:do fish have the capacity for pain perception and suffering. Animal Welfare, 13, S87-92

Brambell FWR. (1965) Report of the Technical Committee to enquire into the welfare of animals kept under intensive livestock husbandry systems. London: HMSO Cmnd. 2836

FAO (2007) The State of World Fisheries and Aquaculture 2006, Rome FAO

Huntingford, F. A., Adams, C., Braithwaite, V. A, Kadri, S., Pottinger, T. G., Sandøe, P., \& Turnbull, J. F. (2006). Current issues in fish welfare. Journal of Fish Biology, 68, 332-372.

Kaiser, M. and Forsberg, E.M. (2001). Assessing fisheries - using an ethical matrix in a participatory process. Journal of Agricultural and Environmental Ethics, 14: 192-200.

Millar, K. M., Gamborg, C. and Sandøe, P. (2007). Using participatory methods to explore the social and ethical issues raised by bioscience research programmes: the case of animal genomics research. In: Sustainable food production and ethics (Zollitisch, W., Winckler, C., Waiblinger, S. \& Haslberger, A., eds.), pp. 354-359.Wageningen: Wageningen Academic Publishers

Sandøe, P. and Christiansen, S. B. (2008). Ethics of animal use. Oxford: Blackwell.

Turnbull, J. F. and Kadri, S. (2007). Safeguarding the many guises of farmed fish welfare. Diseases of Aquatic Organisms 75, 173-182. 